\title{
First Visit with All Necessary Components to Determine
}

National Cancer Institute

\section{Source}

National Cancer Institute. First Visit with All Necessary Components to Determine. NCI

Thesaurus. Code C159707.

An indication of the first visit during which all components needed to determine something were present. 